\title{
Factors that drive energy use in Africa: Panel Data evidence from selected Sub-Sahara African Countries
}

\author{
Aisha Kolawole1, Sola Adesola ${ }^{2}$, Glauco De Vita ${ }^{3}$ \\ ${ }^{1,2}$ Faculty of Business, Oxford Brookes University, Oxford OX33 1HX \\ ${ }^{3}$ Centre for Business in Society, Faculty of Business and Law, Coventry University, Coventry CV1 \\ $5 \mathrm{FB}$
}

\begin{abstract}
Sub-Saharan African (SSA) countries need adequate energy to achieve socio-economic growth and development. According to recent statistics, only 30 per cent of the entire population have access to power, making the region the highest in the world with people without access to electricity. This is in sharp contrast with the abundant energy resources available, which could be harnessed to provide the needed energy. The purpose of this study is to identify and analyse the determinants of aggregate energy demand in SSA. Reliable secondary macroeconomic and energy data were collected from publicly available and widely used databases. The study uses a panel cointegration technique to examine the determinants of energy demand in SSA, over the period 1980 to 2014, for selected countries in the region. Our results reveal that income is the predominant factor behind the increase in energy demand in SSA, with the highest elasticity. Further, energy demand in SSA conforms to a priori expectations of a negative price elasticity. The results are in line with the theory of demand. Significantly, we also find that urbanisation an important role for energy demand. Stringent energy conservation policy and other recommendations flow from the findings.
\end{abstract}

\section{Keywords: Energy demand, Panel cointegration, SSA}

\section{Introduction}

The need for a comprehensive and up-to-date energy demand analysis in Sub-Saharan Africa (SSA) cannot be overemphasised. SSA population is $13 \%$ of the World population but only accounts for $4 \%$ of the total global energy consumed (IEA, 2014). Also, the primary source of energy in the region is solid biomass like fuelwood and charcoal which accounts for more than $75 \%$ of the total energy consumed in the region (Lambe et al., 2015). Another issue is the increase in urban population from $22.1 \%$ in 1980 to $37 \%$ in 2014 (World Bank, 2014). The region has the highest number of people without access to electricity in the world, estimated at 600 million (Onyeyi, 2014). The low rate of 
electrification is in contrast with other developing regions such as Developing Asia, Latin America and the Middle East with electricity access rate of $86 \%, 95 \%$ and $92 \%$, respectively (IEA, 2013). However, there are abundant renewable and non-renewable energy resources which could be used to provide the energy needed. This is in sharp contrast with the energy poverty.

The main objective of this study, therefore, is to investigate the impact of the driving forces of aggregate energy demand in SSA, in order to facilitate demand planning and management. To achieve this goal, the impact of income, price, urbanisation and economic structure on the demand for energy in SSA is analysed and presented. The panel dataset covers the period from 1980 to 2014, covering 16 SSA countries, namely: Benin, Botswana, Cameroon, Congo, Cote D'Ivoire, Democratic Republic of Congo, Ethiopia, Ghana, Mozambique, Nigeria, Senegal, South Africa, Sudan, Togo, Zambia and Zimbabwe. The findings can facilitate the development of an appropriate policy framework for meeting the energy need of consumers in SSA, once the underlying driving factors are analysed. The paper provides fresh evidence in the energy economics literature on the determinants of aggregate energy demand in SSA by analysing an up-to-date dataset for 16 countries in the region.

The remaining part of the paper proceeds as follows. Section 2 provides a brief review of the empirical literature on energy demand. Section 3 discusses the data and econometric framework employed in the analysis. Section 4 presents the empirical results and Section discusses the findings. The final section provides a summary of findings and offers some policy implications.

\section{Review of Related Literature}

Several researchers have used various methods and approaches to model energy demand and obtained different results, which have either confirmed or contradicted earlier studies. Some of such studies in the literature include those by Al-faris (1992), Eltony and Hoque (1996), Mohammad and Eltony (1996), Masih and Masih (1996a \& b), Brenton (1997), Diabi (1998), Galli (1998), Pesaran et al. (1998), Sinton and Fridley (2000), De Vita et al. (2006) and Wolde-Rufael (2006). They are based on the law of demand and the assumption that the demand for energy mostly behaves as a normal good, which suggests 
that the main variables that influence the demand for energy are price and income (see Appendix 1 for mathematical derivations).

As pointed out by Samuel et al. (2013), the key determining variables for the demand for energy include per capital real GDP, industrial growth, real price of energy, population, air temperature, financial development variables, capital stock, foreign direct investment and efficiency variables. The use of some of these variables, with the price and income variables in the model specification, is largely dependent on data availability, and the technique used, which has led to different results in terms of size and sign of the elasticities in both the short- and the long-run. Some of the previous studies on energy demand in developing countries are discused below.

Al-Azzam and Hawdon (1999) analysed energy demand in Jordan using a linear log model in the estimation of the Jordan energy demand with a dataset based on the 1968-1997 sample period. The Stock-Watson Dynamic Ordinary Least Squares (DOLS) and the Error Correction Model (ECM) techniques were used to investigate the relationship between energy consumption, real income, real energy prices and construction activity. The price elasticities of energy demand were found to be low and statistically insignificant. The income elasticity of the total energy demanded was found to be close to unity, suggesting that the amount of increase in the demand for energy induced by the growth in the economy is proportional.

Alves and Bueno (2003) studied the short-run, long-run and cross elasticities of gasoline demand in Brazil, using price, income and the price of alcohol as independent variables, within a co-integration model. Alcohol-based fuel was chosen because in Brazil it has been developed as a close substitute to gasoline, and it is commonly used as a major fuel for automobiles. The study covered the period between 1974 and 1999 for all the variables, including gasoline consumption per capita, real per capita GDP, and the real price of gasoline. They found that both price and income had the expected sign, as predicted by demand theory. Also, a positive sign for the cross-price elasticity of gasoline for alcohol was recorded. The result of the cross-price elasticity of alcohol and gasoline from the error correction model, may suggest that in the long-run consumers are not very sensitive to changes in the price of fuel. This is in line with the hypothesis that the price elasticity of gasoline is inelastic in both the short- and long-run. 
In their study on Namibia, De Vita et al. (2006) estimated the demand function at the aggregate level and by specific fuel types (electricity, petrol and diesel), within an autoregressive distributed lag (ARDL) bounds testing approach to cointegration. The results from the estimation of the model conform to theory prediction, that is, the price elasticity was negative while the income elasticity was positive, as we would expect $a$ priori. The empirical study also looked at the price elasticity of each of the different fuel types, and found that the price elasticity of petrol was the highest, followed by that of electricity, with diesel showing no significant price elasticity. Further, the different energy forms gave no evidence of cross price elasticities in the analysis for Namibia, during the study period. This could suggest that consumers do not necessarily change their consumption level or energy mix according to changes in income or prices of the different energy types, as they appear to maintain the use of certain appliances and equipment for energy generation (De Vita et al., 2006).

Akinboade et al. (2008) estimated the demand for gasoline in South Africa between 1978 and 2005, using annual time series data, within an ARDL framework. The results of the analysis show that the demand for gasoline behaves as that for a normal good. However, the demand increases as the income level increases, but not at a proportional rate.

Adom et al. (2012) analysed the driving forces of the domestic demand for electricity both in the short- and long-run in Ghana, for the period from 1975 to 2005, within an ARDL framework. The researchers used a log linear model with the use of annual time series data on real capita GDP, industry efficiency, structural changes in the economy, total domestic electricity consumption and the degree of urbanisation variables. Their study does not take account of the effect of the price variables on electricity demand in Ghana during the period of the study due to lack of relevant data. Therefore, the study did not detect any evidence for the impact of changes in price on electricity in Ghana in the analysis. This would have perhaps made the findings more robust. Furthermore, the inclusion of the impact of structural changes in the analysis is due to the shift towards more energy intensive sectors, which may have led to an increase in the amount of electricity consumed (Adom et al., 2012). The results of the analysis show that, during the study period, real per capita GDP, industry efficiency, the degree of urbanisation and structural changes are the main long-run factors that influence the demand for electricity in Ghana. Surprisingly, the authors found the coefficient of industry efficiency to be negative and significant. The results suggest that energy in the form of electricity is saved, as firms make use of more 
energy efficient technology in their production process, thus, reducing the overall energy intensity through a reduction in the industry electricity intensity. In other words, there should be appropriate electricity efficiency policies and regulations for each sector of the country. These results are consistent with those obtained by Adom (2013) who also found that income, industry efficiency and economic structure are the main factors that impact electricity consumption in Ghana.

Mensah (2014) explored the modeling of demand for LPG in Ghana using two techniques. Specifically, Mensah (2014) stated that the use of the ARDL and PAM (Partial Adjustment Model) techniques in his study serve the purpose of identifying the best model to be used for a 10 year forecast of the fuel. The quarterly time series data used in both models, between 1992 and 2012, show that income, price and urbanisation are the main determinants of natural gas demand in Ghana in the long-run. The author added that the ARDL is a better model for forecasting future LPG consumption. This led to the use of this model by the author to forecast 10 year ex-ante demand for LPG in Ghana, based on the three different scenarios presented by the researcher. The result of the projections from the three scenarios gave evidence that the demand for LPG might, by the year 2022, reach a minimum value of 5.0 million metric tons (Mensah, 2014).

A cross-country study of the factors that drive energy demand in SSA is provided by Keho (2016), who used the bounds testing approach to cointegration at individual country level between 1970 and 2011. The author found that in the 12 countries analysed, economic growth, industrial output and population are the major drivers of energy demand.

The knowledge from the studies reviewed above is employed in building the empirical model used in this paper. To fully implement an effective energy demand management strategy, it is important to understand fully the impacts of economic and non-economic factors on energy demand in SSA. In line with this, this study seeks to fill the identified gap in the literature by providing a comprehensive and up-to-date analysis of the determinants of energy demand in SSA.

\section{Model specification and econometric strategy}

The model adopted in this study is based on the neo-classical economic theory of consumers utility optimising behavior. The microeconomics concept is used as the 
framework for the analysis at the macro level. The demand function for energy demand in SSA is analysed in the study, using a log-linearised model. We specify SSA demand function as:

$\ln E_{i t}=\alpha_{0}+\alpha_{1} \ln Y_{i t}+\alpha_{2} \ln P_{i t}+\alpha_{3} \ln U r B_{i t}+\alpha_{4} \ln E S_{i t}+\rho_{t}$

where $\ln E_{i t}$ is the natural $\log$ transformation of energy consumption in country $\mathrm{i}$ at time $\mathrm{t}$; $\ln \mathrm{Y}, \ln U r B, \ln \mathrm{P}$ and $\operatorname{lnES}$ stand for the logs of income (GDP/Capita), urbanisation, price and economic structure in country $i$ at time $t$, respectively. The demand elasticities are measured by parameter $\alpha$ while the white noise error term is denoted by $\rho$.

Based on economic theory of demand and the literature reviewed, a priori, we expect the following in terms of the sign of the estimated parameters. First, we expect a positive income elasticity, as the income level of consumers goes up, they increase the amount of commodities in their consumption bundle which includes energy. Economic growth is seen as the main determinant of energy consumption. Second, in line with demand theory, a negative price elasticity is expected because theory suggests that as the price to be paid for commodities increases, consumers will reduce their consumption level of that commodity. Thus, an increase in energy price is expected to reduce the amount of energy consumed. Third, growth in urban population (urbanisation) is expected to have a positive impact on the amount of energy consumed. As people move from rural to urban areas, it is assumed that they switch from traditional forms of energy like solid biomass to modern energy types like electricity and gas. Lastly, we expect a positive relationship between energy demand and economic structure. From the reviewed literature, economic structure for a country is derived by using the share of industrial value added to the services value added, which is also used to measure the impact of structural changes in a country. An increase in industrial share or output will increase the total amount of energy consumed.

To verify the stated hypotheses, the panel cointegration technique is used. The technique could be divided into three main steps. First, the unit root properties of the variables are examined using the Fisher panel unit root test based on Dickey Fuller (1978) and Im, Pesaran and Shin (2003). After confirming that the time series are stationary, the Westerlund panel error correction based cointegration test is used to test for cointegration 
in the series. After cointegration is established among the variables, the short-run and longrun impact of the independent variables on energy demand in Sub Saharan Africa (SSA) is estimated using the technique of Pooled Mean Group (PMG) estimator error correction model.

\subsection{Data description}

\section{$<$ Table I about here $>$}

The paper employs annual time series data for a panel model of 16 Sub Saharan African countries, namely Benin, Botswana, Cameroon, Congo, Cote D'Ivoire, Democratic Republic of Congo, Ethiopia, Ghana, Mozambique, Nigeria, Senegal, South Africa, Sudan, Togo, Zambia and Zimbabwe. Inevitably our country sample selection is dictated by data availability. We should acknowledge that despite the value of average statistical analysis, these countries do not necessarily constitute a homogenous set. Some countries like Botswana, Nigeria and South Africa are either strongly relying on one important single good as diamonds (Botswana) or oil (Nigeria) or have at least in part a substantially developed industrial sector (South Africa), while most of the other countries in our sample are mainly at an agricultural development stage. Additionally, it should be borne in mind that the starting point for urbanisation may be very different among the selected countries.

The scatter plot of the relationship between the natural log $(\ln )$ of energy demand and the natural $\log (\ln )$ of income is presented in Figure 1. The scatter plot shows an ambiguous relationship between the plotted variables since only the far right data points would indicate a pattern consistent with a positive relationship between the variables in question, thus making our cointegration analysis results to be presented below all the more important to confirm the relationship predicted by theory. 


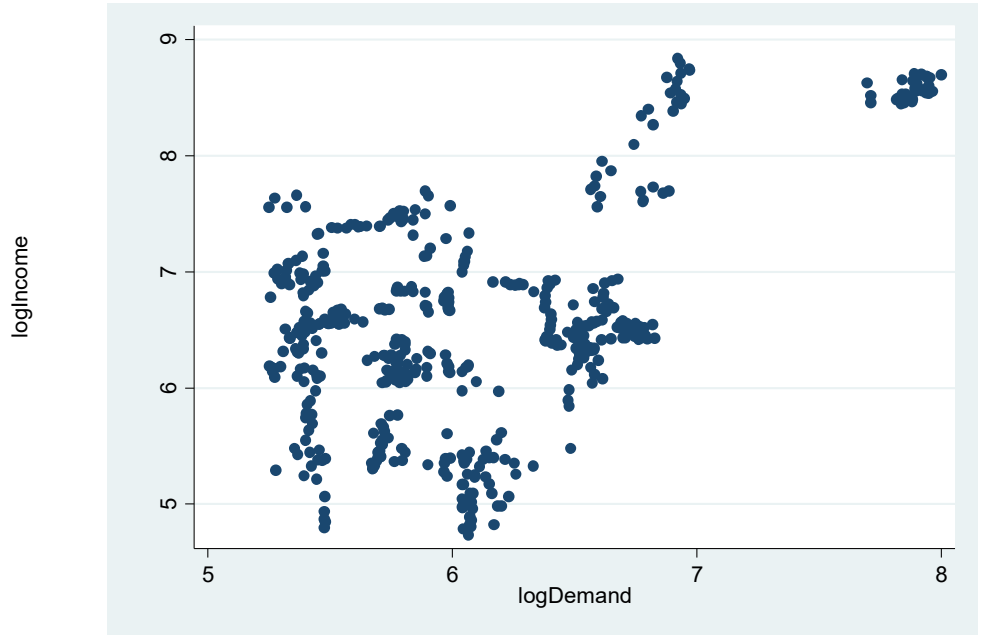

Figure 1 Scatter plot of energy demand and income variable

\section{Estimation Results}

The results of the analysed panel data model are presented in this section of the paper. Each step of the analysis is presented in sequence below.

\subsection{Panel unit root tests results}

Three panel unit root tests are employed to determine the stationarity properties of the variables in the model. That is, the Im-Pesaran-Shin unit root test and the two Fisher type (based on Augmented Dickey Fuller and the Phillips-Perron) panel unit root tests. The results of the panel unit root tests carried out to establish the unit root properties of the variables are shown in Table II below. The tests chosen are those that give unbiased estimates even in an unbalanced panel.

$<$ Table II about here $>$

All three tests have the same null hypothesis of the series containing a unit root. The energy demand and economic structure variable series based on the three tests performed, gave strong evidence that the variables are stationary both in levels and, obviously, in first difference. The log of income and price are non-stationary in levels, that is, they contain a unit root in levels but after first differencing, the series become stationary. Lastly, the 
urbanisation variable gave evidence of stationarity in levels under the IPS and ADF-Fisher tests in levels but the results are in contrast with that of PP-Fisher panel unit root test which showed that the urbanisation series is non-stationary in levels. However, the mixed result was clarified when the first difference of the series was taken and all three tests gave strong evidence of stationarity. It is apparent from Table Il that there is a mixed order of integration among the variables in levels.

Having established that there is a mixed order of integration among the variables, we can now proceed to investigate the long-run relationship between the variables, and whether there is, in fact, a statistically significant cointegrating relationship using the Westerlundbased panel cointegration test. The work of Pesaran et al. (2001) has shown that there exists a possibility of a long-run cointegration relation among series of differing order of integration (that is $\mathrm{I}(0)$ and $\mathrm{I}(1)$ ). Based on this - and following the approach of Frimpong and Adu (2014), Martins (2006), and Morshed (2010) - we proceed to examine the cointegration relationship among the variables in this study.

For instance, Frimpong and Adu (2014) examined the long run cointegration relationship between real GDP per capita, human capital, physical capital formation, openness and a set of human health indicators on a panel data set of 30 SSA countries between 1970-2010, using the Westerlund cointegration approach, and the PMG error correction technique to estimate the long- and short-run determinants of growth, in the presence of a mixed order of integration.

An advantage of using the PMG error correction approach especially in the context of this study is that the PMG technique is a panel extension of the Autoregressive Distributed Lag (ARDL) model popularly used in time series analysis due to its ability to estimate a cointegration relationship among the variables even when the regressors have a different order of integration. The evidence above gives enough bases for this study, to proceed with the long-run analysis even when the variables have different order of integration. The test was also chosen because it is robust enough to allow for high level of heterogeneity in the short-run as well as in the long-run cointegrating relationship, even in an unbalanced panel (an important feasture given the potential heterogeneity of the countries in question discussed earlier).

\subsection{Panel cointegration results}


The Westerlund-based panel cointegration test is used to ascertain whether the variables move together in the long-run. This cointegration test is used to establish if energy demand, income, degree of urbanisation, oil price and economic structure are cointegrated. We specify a single lead and lag based on a constant and a trend using 150 replications through a bootstrapping procedure. Bootstrapping is used to correct for correlation among the crosssectional units of the panel, thus giving robust critical values. The results obtained from the tests are presented in Table III below.

\section{$<$ Table III about here $>$}

As Table III shows, robust $p$-values under one of the cross sectional statistics (Ga) and the two panel statistics ( $\mathrm{Pt}$ and $\mathrm{Pa}$ ) give evidence that the null hypothesis of 'no cointegration' can be rejected. Rejection of one of the cross sectional statistic (Gt or Ga) is sufficient evidence against the null hypothesis. Interestingly, both $\mathrm{Pt}$ and $\mathrm{Pa}$ robust $p$-values give strong evidence against null at the $1 \%$ significance level. Therefore, we have strong evidence of cointegration among the variables in our aggregate energy demand model. Since we have ascertained that there is cointegration among the variables, we can safely proceed to estimate the long-run relationships among the variables.

\subsection{Results of the long run aggregate energy demand relationships}

Having established the existence of cointegration, that is, that the variables in the model do move together in the long-run forming an economically meaningful and statistically significant relationship, this section presents the results of the long-run determinants of energy demand in Sub-Saharan Africa, based on the results of the Pooled Mean Group (PMG) estimator error correction model.

\section{<Table IV about here $>$}

From Table IV, it is apparent that all the variables have the expected sign except for the economic structure variable. The changes in price and income have the expected theoretical sign as discussed above. Specifically, a 1\% increase in consumers' income will lead to a 
$0.10 \%$ increase in energy consumption in SSA. The coefficient is strongly significant, at the $1 \%$ level, which implies that in the long run consumers will adjust and increase the amount of goods in their consumption bundles as they earn more. This includes both energy and non-energy goods but it should be noted that the elasticity is relatively inelastic in the long run. It is evident from this that the demand for energy is inelastic because the changes in income lead to a smaller increase in the amount of energy consumed. In fact, the change in the consumption level is very small when compared to the increase in the consumers' income from the result reported.

The estimated coefficient of the energy price variable also gives evidence of a negative elasticity and it is significant at the 5\% level. The estimated coefficient indicates that a $1 \%$ increase in energy price leads, on average, to a $0.46 \%$ reduction in the amount of energy consumed; a plausible result which is economically meaningful. It also confirms that energy demand is inelastic in the long-run in SSA as stated earlier, perhaps because energy is an essential good to most consumers.

Also, the estimated coefficient of the degree of urbanisation is statistically significant and the coefficient sign is as expected a priori. Energy demand appears to increase by $0.01 \%$ for every $1 \%$ increase in the population of urban areas in SSA. This may be due to the fact that when consumers move to urban areas, they move towards the use of more modern energy types, appliances and gadgets which may be linked to the increase in income level.

The estimated elasticity of the economic structure variable does not have the expected sign and is not statistically significant. A negative elasticity is found which is probably due to the shift from industrial sector to service sectors in SSA in the last few decades, but the fact that the coefficient turns out to be statistically insignificant means that it is meaningless to interpret its sign or magnitude.

\subsection{Results of the short run aggregate energy demand relationships}

The results of the estimated short-run determinants of energy demand in SSA are presented and discussed in this section.

$<$ Table V about here $>$ 
An important component of the error correction model (ECM) is the error correction term (henceforth, ' $e c$ '), which is expected to be negative and statistically significant. The result of this study confirms this because the $e c$ is negative (-0.538) and statistically significant at the $1 \%$ level ( $p$-value of 0.000 ). The $e c$ shows that every year, $53.8 \%$ deviation of the variables from long-run equilibrium is corrected, hence it takes just short of two years for short-run deviations or shocks to the variables to return to their 'equilibrium' level, i.e., long-run values.

All the variables except the income and price variables have the signs expected a priori. The results confirmed that for every $1 \%$ rise in urban population, there will be a significant increase of $0.14 \%$ in energy demand in SSA. Likewise, for every $1 \%$ increase in industrial output there will be an increase of $0.03 \%$ in energy consumption.

However, the result of the income elasticity is in contrast of what we expected a priori. This might be due to the low income levels in most of the analysed countries, and going by short-run economic analysis, even when there is an increase in income it will take some time for consumers to adjust their consumption bundle to reflect this change. The same goes for the price variable which shows a positive price elasticity. This might also be because the demand for energy is inelastic and there are no close substitutes for most liquid fuels like kerosene and LPG, or consumers are less responsive to changes in price in the short-run. But, considering that the income coefficient is not statistically significant, the result should be interpreted with caution. In this study, we are more concerned with the long-run analysis.

\section{Discussion of findings}

This study sets out with the aim of estimating the coefficients of the identified driving forces of energy demand in SSA. As stated earlier, this study is more interested in the long run estimates from the error correction model employed to align with the main aim of the research. The main question in this paper seeks to identify and analyse the factors that drive energy demand in the long-run in SSA. As expected, our results found support for the theoretical positive relationship between energy demand and income. 
Similarly, the theoretically expected negative relationship between energy price and energy demand was also confirmed by the results. Hence, energy is a normal good. Both are consistent with the results presented in existing literature. Al-Azzam and Hawdon (1999) had an income and price elasticity of 0.95 and -0.22 respectively in Jordan, Iwayemi et al. (2010) had an income elasticity of 0.81 and price elasticity of -0.11 in Nigeria. Our result is further corroborated by the findings reported by Amusa et al. (2009) in relation to South Africa, Kuma (2008) for Fiji and De Vita et al. (2006) for Namibia.

All the studies highlighted so far, however, suffer from the fact that the impact of growth in urban population known as the degree of urbanisation and economic structure were not included in the models. This is one significant contribution of the present study since it has been accepted by many scholars that urbanisation and changes in the structure of the economy is one of the main drivers of energy demand or consumption in developing countries (Mensah et al., 2016; Adom et al., 2012).

Recently, Keho (2016) attempted to fill this gap by including urbanisation in the study he conducted. He found a negative relationship between energy use and urbanisation in a sample of 12 Sub-Saharan African countries, which is in contrast with our result of a positive impact. The difference in result may be due to differences in the econometric technique used and dataset employed. Indeed, Keho's sample of SSA countries includes oil-rich Gabon and East Africa's leading country, Kenya. The conflicting results between our study and that by Keho (2016) may also be a result of different development stages of the sample members of Keho's and the present study.

The positive relationship found between urbanisation and aggregate energy demand is interesting because, according to a report by the African Development Bank, the annual rate of urbanisation is about $3.5 \%$ with $32.8 \%$ of people in SSA living in cities (AfDB, 2012). Besides, most of the stock of vehicles, modern energy equipment and gadgets are in urban areas. And most houses in the urban areas are connected to the national grid which will lead to an increase in energy use by the consumers who can now acquire more electrical gadgets as they move from rural to urban areas with increased access to electricity. It is, therefore, expected that an increase in urban population size will increase the overall amount of energy consumed, as found in our analysis. 


\section{Conclusion and policy implications}

In this study we examined the determinants of energy demand in Sub-Saharan Africa (SSA) over the period 1980 to 2014, for 16 countries in the region. Our PMG result suggests that income is the predominant factor behind the increase in energy demand in SSA, with the highest elasticity. Further, energy demand in SSA conforms to a priori expectations of a negative price elasticity. Significantly, the urbanisation elasticity is found to be positive and strongly statistically significant in the present study. This is a key finding indicating that urbanisation will continue to play an important role for energy demand in the future.

Our findings appear to have important policy implications for a developing region such as SSA. First, there is need to promote regional integration and cooperation of energy supply to meet the need of consumers. As reviewed in the literature, by investing in regional power generation, the countries can benefit from economies of scale, lower investment costs and wider choice. The revenue needed for the projects can be generated from both private and public sources since there is demand for energy if made available.

Second, according to the findings, increase in income will increase energy demand in the region. Therefore, there is need for stringent energy conservation policies through effective energy efficiency practice, to ensure that increase in energy use does not lead to more greenhouse gas (GHG) emission and the produced energy is well utilised. For instance, the government should ensure that appliances and gadgets sold to consumers comply with recommended energy efficiency standards to reduce the overall energy intensity. However, more energy should first be provided to meet the energy need of the consumers, in order to achieve socio-economic development in the region.

Lastly, countries in SSA can reduce their overall carbon emission, and also provide the energy needed by consumers, through investment in clean and green energy sources using the vast renewable resources available. To encourage the use of renewable energy sources and to make it affordable, it is recommended that governments in SSA reduce import duty and provide subsidies on renewable energy sources like solar and wind energy. This will also improve the standard of living and economy, especially for off-grid rural areas with no access to the national grid. It will also increase electrification rates across the region and may help to reduce rural-urban migration in the long run. 


\section{REFERENCES}

Adom P, Bekoe W, Akoena SK. (2012); Modelling aggregate domestic electricity demand in Ghana: An autoregressive distributed lag bounds cointegration approach; Energy Policy, pp.530-537.

Adom P. (2013); Time varying analysis of aggregate electricity demand in Ghana: a rolling analysis; OPEC Energy Review, pp.63-80.

Afdb (2012) Urbanization in Africa. Available: http://www.afdb.org/en/blogs/afdbchampioning-inclusive-growth-across-africa/post/urbanization-in-africa-10143/. Accessed 7 April 2016.

Akinboade O, Ziramba E, Kumo, W. (2008); The demand for gasoline in South Africa: An empirical analysis using co-integration techniques; Energy Economics, pp.3222-3229.

Al- faris A. (1992); Income and price elasticity of gasoline demand in Organization of Arab Petroleum Exporting Countries; Journal of Energy and Development, pp.209-223.

Al-Azzam A, Hawdon D. (1999); Estimating the demand for energy in Jordan: A StockWatson dynamic OLS (DOLS) approach, Surrey Energy Economics Centre, Department of Economics, University of Surrey, pp.1-17.

Alves DC, Bueno RD. (2003); Short- run, long-run and cross elasticities of gasoline demand in Brazil; Energy Economics, pp.191-199.

Amusa H, Amusa K, Mabugu, R. (2009); Aggregate demand for electricity in South Africa: An analysis using the bounds testing approach to cointegration; Energy Policy, pp.4167- 4175.

Brenton P. (1997); Estimates of the demand for energy using cross-country consumption data; Applied Economics, 29, pp.851-859.

De Vita G, Endersen K, Hunt LC. (2006); An empirical analysis of energy demand in Namibia; Energy Policy, 34, pp.3447-3463.

Diabi A. (1998); The demand for electric energy in Saudi Arabia: an empirical investigation; OPEC Energy Review, pp.13-24. 
Eltony M, Hoque A. (1996); A cointegrating relationship in the demand for energy: The case of electricity in Kuwait; Journal of Energy and Development, 21, pp.293-301.

Frimpong PB, Adu G. (2014); Population Health and Economic Growth in Sub-Saharan Africa: A Panel Cointegration Analysis; African Business, 15, pp.36-48.

Galli R. (1998); The relationship between energy intensity and income levels: forecasting long term energy demand in Asian emerging countries; Energy 19, pp.85-105.

IEA (2013); World Energy Outlook. International Energy Agency (IEA), Paris.

IEA (2014); World Energy Outlook 2014 Special Report: Africa Energy Outlook, International Energy Agency (IEA), Paris.

Iwayemi A. (2008); Nigeria's Dual Energy Problems: Policy Issues and Challenges; International Association for Energy Economics.

Keho Y. (2016); What drives energy consumption in developing countries? The experience of selected African countries; Energy Policy, 91, pp.233-246.

Kuma S. (2008); Cointegration and the demand for Energy in Fiji; Munich Personal RePEc Archive, pp.1-16.

Lambe F, Jürisoo M, Wanjiru H, Senyagwa J. (2015); Bringing clean, safe, affordable cooking energy to households across Africa: an agenda for action; Prepared by the Stockholm Environment Institute, Stockholm and Nairobi, for the New Climate Economy. Available: http://newclimateeconomy.report/misc/working-papers.

Martins PMG. (2006); Aid Absorption and Spending in Africa: A Panel Cointegration Approach; Credit Research paper 10/06.

Masih A, Masih R. (1996a); Energy consumption, real income and temporal causality: results from multi country based on cointegration and error correction modelling technique; Energy Economics, pp.165-183.

Masih AM, Masih R. (1997b); On the Temporal Causal Relationship between Energy Consumption, Real Income, and Prices: Some new Evidence from Asian-Energy Dependent NICs based on a Multivariate Cointegration/Vector Error-Correction Approach; Policy Modeling, 19, pp.417-440. 
Mensah JT. (2014); Modelling demand for liquefied petroleum gas (LPG) in Ghana: current dynamics and forecast; OPEC Energy Review, 398-423.

Mensah JT, Marbuah G, Amoah A. (2016); Energy demand in Ghana: A disaggregated analysis; Renewable and Sustainable Energy Reviews, pp.924-935.

Mohammed Y, Eltony M. (1996); The demand for natural gas in the Gulf Cooperation Council (GCC) states; Middle East Business and Economic Review, 8, pp.41- 48.

Morshed HAS. (2010); A Panel Cointegration Analysis of the Euro area money demand; Department of Statistics, Lund University.

Onjeyi I. (2014); Harnessing and integrating Africa's renewable energy resources; New Energy Insights, 3, pp. 27-38.

Pesaran M, Smith R, Akiyama T (1998); Energy demand in Asian economie; Oxford: Oxford University Press.

Pesaran MH, Shin YC, Smith R. (2001); Bounds testing approaches to the analysis of level relationships; Applied Econometrics, 16, pp.289-326.

Samuel Y, Manu O. and Wereko T. (2013); Determinants of energy consumption: A review; International Journal of Management Sciences, pp.482-487.

Sinton J, Fridley D. (2000); What goes up: recent trends in China's energy consumption; Energy Policy, 28, pp.671- 687.

Wolde-Rufael. (2006); Disaggregated industrial energy consumption and GDP: the case of Shanghai 1952-1999; Energy Economics, pp.69-75.

World Development Indicators, World Bank: http://data.worldbank.org/region/SSA, accessed 5 December, 2016.

\section{Appendix 1}

First, the utility function of a consumer is represented by

$\mathrm{U}=\mathrm{U}\left(X_{1}, X_{\mathbf{2}}, X_{\mathbf{3}}, \ldots \ldots \ldots \ldots, X_{n}\right)$ 
The budget constraint of the consumer can be written as

$\mathrm{Y}=P_{1} X_{1}+P_{2} X_{2}+P_{3} X_{3}+\cdots \ldots \ldots \ldots \ldots+P_{n} X_{n}$

Next, the Lagrange (L) is set so as to maximise the consumer's utility subject to the budget constraint:

$\mathrm{L}=$

$\mathrm{U}\left(X_{1} 1, X_{\downarrow} 2, X_{1} 3, \ldots \ldots, X_{\downarrow} n\right)-\lambda\left(Y-\left(P_{\downarrow} 1 X_{1} 1+P_{\downarrow} 2 X_{1} 2+P_{\downarrow} 3 X_{\downarrow} 3+\ldots \ldots+P_{\downarrow} n X_{\downarrow} n\right)\right)$

(III)

The partial derivatives of $\mathrm{L}$ are set with respect to $X_{1}, X_{2}, X_{3}, \ldots \ldots \ldots \ldots \ldots, X_{n}$, while $\lambda$ is set to zero in all the equations to obtain the necessary conditions

$\partial l / \partial X_{1}=\partial U / \partial X_{1}-\lambda P_{1}=\mathbf{0}$
$\partial l / \partial X_{\mathbf{2}}=\partial U / \partial X_{\mathbf{2}}-\lambda P_{\mathbf{2}}=\mathbf{0}$
$\partial l / \partial X_{\mathbf{a}}=\partial U / \partial X_{\mathbf{a}}-\lambda P_{\mathbf{a}}=0$

$\vdots$

$\vdots$

$\partial l / \partial X_{n}=\partial U / \partial X_{n}-\lambda P_{n}=\mathbf{0}$

$\partial l / \partial \lambda=Y-P_{1} X_{1}+P_{\mathbf{2}} X_{\mathbf{2}}+P_{\mathrm{a}} X_{\mathrm{a}}+\cdots \ldots \ldots+P_{n} X_{n}=0$

To solve the equations above, one can equate them to one another and solve for lambda, to get the marginal rate of substitution $(M R S)$, i.e., the marginal rate of substitution of one commodity for the other

$$
\stackrel{\partial l}{\partial X_{1}} / \partial l / \partial X_{\mathbf{2}}={ }^{P_{1}} / P_{2} \quad \cong M R S=\text { price } \text { ratio }
$$

$\lambda=\frac{\partial U / \partial X_{1}}{P_{1}}=\frac{\partial U / \partial X_{\mathbf{2}}}{P_{\mathbf{2}}}=\ldots \ldots \ldots=\frac{\partial U / \partial X_{n}}{P_{n}}$

The last step is to derive the demand function for energy which is a function of price and income. The assumption here is that both price and income are homogenous of degree zero, and the necessary condition is solved for each equation. The resulting demand equation is represented by the equations: 


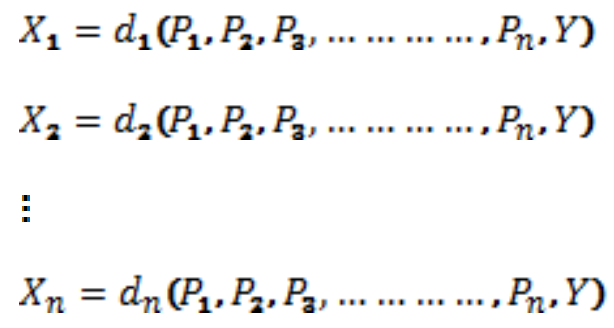

Equation (VI) signifies that the demand for energy is a function of both the relative prices and real income of the consumer.

However, for use in empirical modelling, other factors that are identified to influence the demand for energy are included, which makes the empirical model to be in the form presented in equation (VII) below. Where the vector N, represents other driving factors or forces of energy demand.

$X_{n}=d_{n}\left(P_{1}, P_{\mathbf{2}}, P_{3}, \ldots \ldots \ldots, P_{n}, Y, N\right)$

Table I: Description of the variables employed in the analysis for the period 1980-2014

\begin{tabular}{|c|c|c|c|}
\hline Variable & Definition & $\begin{array}{l}\text { Unit } \\
\text { of measurement }\end{array}$ & Data source \\
\hline Price $(\mathrm{P})$ & Crude oil price & US\$/barrel & World Bank (2015) \\
\hline GDP per Capita (Y) & $\begin{array}{l}\text { Gross domestic product divided by } \\
\text { mid year population }\end{array}$ & $\begin{array}{l}\text { US\$ in PPP }(2005 \\
\text { prices })\end{array}$ & World Bank (2015) \\
\hline Urbanisation (UrB) & $\begin{array}{l}\text { The people living in the urban areas } \\
\text { of a country out of the total } \\
\text { population }\end{array}$ & Percent & World Bank (2015) \\
\hline $\begin{array}{l}\text { Economic Structure } \\
(\mathrm{ES})\end{array}$ & $\begin{array}{l}\text { Real value added in industry divided } \\
\text { by that of the real value added in } \\
\text { service sector }\end{array}$ & Percent & $\begin{array}{l}\text { Calculated using data } \\
\text { from World Bank (2015) }\end{array}$ \\
\hline Energy Demand (E) & Energy use & $\begin{array}{l}\mathrm{Kg} \text { of oil } \\
\text { equivalent/capita }\end{array}$ & World Bank (2015) \\
\hline
\end{tabular}

Table II: Panel unit root tests results for the variables in levels and first differences

\begin{tabular}{lllll}
\hline Variable & IPS Statistics & ADF- Fisher & PP- Fisher & Inference \\
$\ln \mathrm{E}$ & $-3.069^{* *}$ & $7.731^{* * *}$ & $13.391^{* * *}$ & Stationary \\
$\ln \mathrm{Y}$ & 2.979 & -1.347 & -0.867 & Non-stationary \\
$\mathrm{ES}$ & $-2.771^{* *}$ & $4.516^{* * *}$ & $6.479^{* * *}$ & Stationary \\
$\mathrm{UrB}$ & $-2.443^{*}$ & $6.085^{* * *}$ & -1.046 & Mixed \\
$\ln \mathrm{S}$ & 5.557 & -3.775 & -3.274 & Non-stationary \\
& & & \\
\hline
\end{tabular}




\begin{tabular}{lllll}
\hline$\Delta \operatorname{lnE}$ & $-16.597^{* * *}$ & $49.290^{* * *}$ & $86.474^{* * *}$ & Stationary \\
$\Delta \ln \mathrm{Y}$ & $-11.454^{* * *}$ & $27.082^{* * *}$ & $64.513^{* * *}$ & Stationary \\
$\Delta \mathrm{ES}$ & $-12.712^{* * *}$ & $34.301^{* * *}$ & $71.345^{* * *}$ & Stationary \\
$\Delta \mathrm{UrB}$ & $-8.667^{* * *}$ & $16.540^{* * *}$ & $31.852^{* * *}$ & Stationary \\
$\Delta \ln \mathrm{P}$ & $-13.910^{* * *}$ & $0.999^{* * *}$ & $83.806^{* * *}$ & Stationary
\end{tabular}

Notes: $\Delta$ is the first difference operator. $*, * *$ and $* * *$ indicates rejection of the null of a unit root at the significance levels of $10 \%, 5 \%$ and $1 \%$, respectively. $\ln E$ represents the natural $\log$ of energy demand, $\ln Y$ stands for the natural $\log$ of income, ES is the economic structure while UrB stands for the degree of urbanisation. Lastly, $\ln \mathrm{P}$ is the natural $\log$ of energy pricy proxy by oil price. The natural log of the degree of urbanisation and economic structure data series are not taken because they are in percentages.

Table III: Results of the Westerlund-based panel cointegration tests

\begin{tabular}{|c|c|c|c|}
\hline Statistic & Value & Z-value & Robust P-value \\
\hline Gt & -2.585 & 1.230 & 0.260 \\
\hline $\mathrm{Ga}$ & -8.611 & 4.050 & 0.070 \\
\hline $\mathrm{Pt}$ & -11.141 & -0.632 & 0.010 \\
\hline $\mathrm{Pa}$ & -10.981 & 1.351 & 0.000 \\
\hline
\end{tabular}

Table IV: Results of the long run estimates

\begin{tabular}{ll}
\hline Regressors & $0.099^{* * *}$ \\
InIncome & $(0.000)$ \\
& $-0.456^{* *}$ \\
InPrice & $(0.022)$ \\
& $0.013^{* * *}$ \\
Urban & $(0.007)$ \\
&
\end{tabular}


$(0.095)$

Notes: The dependent variable is the log of energy demand, $p$ values are in parentheses, $* * * \mathrm{p}<0.01, * * \mathrm{p}<0.05, * \mathrm{p}<0.1$.

Table V: Results of the ECM estimates in the short run

\begin{tabular}{ll}
\hline Regressors & -0.059 \\
InIncome & $(0.682)$ \\
& $0.238^{* * *}$ \\
InPrice & $(0.00)$ \\
& $0.137^{* *}$ \\
Urban & $(0.055)$ \\
& 0.031 \\
Ecostruc & $(0.795)$ \\
\end{tabular}

Notes: The error correction term which measures the speed of convergence to long-run equilibrium from the model analysis is $-0.538^{* * *}$, the dependent variable is the log of energy demand, $p$-values are in parentheses, ${ }^{* * *} \mathrm{p}<0.01,{ }^{*} * \mathrm{p}<0.05, * \mathrm{p}<0.1$. 